\title{
BMJ Open Changes in South Korean urbanicity and suicide rates, 1992 to 2012
}

\author{
Chee Hon Chan, ${ }^{1,2}$ Eric D Caine, ${ }^{3,4}$ Sungeun You, ${ }^{5}$ Paul Siu Fai Yip ${ }^{1,2}$
}

To cite: Chan $\mathrm{CH}$, Caine $\mathrm{ED}$, You S, et al. Changes in South Korean urbanicity and suicide rates, 1992 to 2012. BMJ Open 2015;5:e009451. doi:10.1136/bmjopen-2015009451

- Prepublication history and additional material is available. To view please visit the journal (http://dx.doi.org/ 10.1136/bmjopen-2015009451)

Received 22 July 2015 Revised 30 September 2015 Accepted 9 November 2015

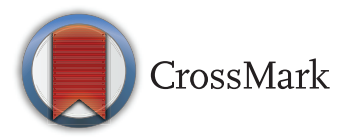

${ }^{1}$ Department of Social Work and Social Administration,

The University of Hong Kong, Hong Kong

${ }^{2}$ Hong Kong Jockey Club Centre for Suicide Research and Prevention,

The University of Hong Kong, Hong Kong

${ }^{3}$ Injury Control Research Center for Suicide Prevention and Department of

Psychiatry, University of Rochester Medical Center, Rochester, New York, USA

${ }^{4}$ VA Center of Excellence for Suicide Prevention, Canandaigua, New York, USA ${ }^{5}$ Department of Psychology, Chungbuk National University, Republic of Korea

Correspondence to Dr Chee Hon Chan; gchc@hku.hk

\section{ABSTRACT}

Objectives: Studies have highlighted the association between the degree of urbanicity and spatial disparities in suicide, but few have evaluated its changes across time. We explored the geospatial trends of suicide in South Korea from 1992 to 2012, and their relationship to the nation's evolving urbanicity.

Setting: South Korea.

Primary outcome measures: Age-sex-specific suicide rate.

Results: Suicide rates increased in all regions of South Korea during the study period. Controlling the effects of age and sex, there was an overall inverse relationship between the degree of urbanicity and regional suicide rates. These associations were, however, attenuated across the periods, as there were smaller increases in suicide rates in mid-sized urban regions as compared to larger cities and to rural areas. Increases over time in the suicide rates among youth and working-age adults were greater in large urban centres and in rural regions. For elders, the increase was far greater in rural regions.

Conclusions: The association of urbanicity and the geospatial pattern of suicide in South Korea was a dynamic process and varied by age groups across the course of two decades. Internal migration and related social processes most likely contributed to these changes.

\section{INTRODUCTION}

Cross-sectional studies have highlighted that suicide rates differ greatly across geographical regions in the same country, but that the nature of such findings are inconsistent. While some studies have noted higher suicide rates in urban settings, ${ }^{1-5}$ others have reported that risks for suicide are relatively greater among rural dwellers. ${ }^{6-12}$ Studies have also highlighted that the geospatial inequalities in suicides changed across time. In some developed Western countries (eg, Australia, Austria, England and Wales, and the USA), spatial disparities in suicide rates have grown due to greater relative increases among rural residents as compared with their urban counterparts. ${ }^{4}{ }^{5} \quad{ }^{13-15}$ Other studies have suggested that such spatial

\section{Strengths and limitations of this study}

This is the first study addressing the temporal changes of the geographical patterning in suicide among all the population in South Korea.

- The results of this study were based on a large national representative sample with the observatory period lasting for 21 years.

- Potential limitations include the use of an ecological study design and changes in data quality of the suicide statistics over the course of the study period.

- This study highlights the profound changes in the geospatial pattern of suicides in South Korea and its potential link with internal migration.

differences have reflected a relative decline in urban areas. ${ }^{3}{ }^{16}$ Changes in spatial disparity of suicide also have been reported to vary by age and sex differences in population composition. ${ }^{3}$

Assessments of spatial trends in suicide rates are uncommon for Asian countries. Suzuki et al examined the spatial pattern of suicide in Japan at the prefecture level and found that the suicide rate of men in the rural region was greater. They also noted that the urban-rural variation in men had widened from 1975 to $2005 .{ }^{17}$ Chen $e t a l^{18}$ in Taiwan reported that the suicide rate of those in rural areas decreased at a faster pace than those of their urban counterparts during a period of overall decline; in contrast, during a time of overall increase, the rate rose more quickly in urban communities. ${ }^{18}$ In South Korea, various cross-sectional investigations have shown a higher suicide rate among rural residents. ${ }^{19-21}$ Two recent Korean studies found that suicide rates among more economically deprived areas were higher. ${ }^{12}{ }^{22}$ With one exception, ${ }^{23}$ few have explored the geospatial trend of suicide in South Korea.

Contextual factors, such as urban growth and internal migrations, have been proposed to affect the association between urbanicity and suicide rates. ${ }^{13}{ }^{24}$ In Australia and the UK, decline in the rural economies together 
with an out-migration of healthier individuals to urban settings have been suggested to contribute to increased suicide rates among young adults in rural areas. ${ }^{25-27} \mathrm{In}$ Asian countries where the social welfare infrastructure is less developed, a high level of material deprivation has been reported to increase rural dwellers' suicide risk. ${ }^{6} 9$ Among aged populations, social isolation or social disintegration (eg, loneliness and breaks in family ties) also have been noted to increase suicide vulnerability. ${ }^{14} 2829$ Additionally, rural residents have less access to healthcare services, and often use highly lethal methods (particularly agricultural pesticides) when attempting to kill themselves. ${ }^{5} 18$

During recent decades, the rapid economic growth and societal modernisation occurring in South Korea has been associated with powerful sociocultural changes, with intense urban growth and internal migrations. ${ }^{30-32}$ Reports have revealed that, from the 1970 s to the 2000s, more than 30 million Koreans had moved from rural regions to urban centres and the percentage of persons living in urban areas increased by $40 \% .^{30} 33$ During this process, economies in the rural regions deteriorated due to the loss of workforce and the decline of family-based agriculture. Many families shrank from extended networks to nuclear groups, marked by diminished social roles for elders and weaker intergenerational economic and emotional supports. $^{30} 3133$ Several authors have suggested that the impact of such changes has fallen hardest on older rural residents who hold more traditional values, with negative consequences for physical and mental health. ${ }^{34-36}$ In turn, the population influx into urban settings led to overcrowding, housing shortages and a deteriorating living environment. Recent reports have indicated that some second-tier (mid-sized) cities have been gaining in population, while levels in large metropolitan areas (eg, Seoul and Busan) and rural regions have been shrinking. ${ }^{30} 37$

We conducted this study to assess whether these dramatic, region-specific demographic shifts, with their attendant social consequences, may have been linked to significant geospatial changes in South Korea's suicide rates. Specifically, we assessed the association between the degree of urbanicity and suicide rates, examined the impact of age in the country's regions, and evaluated the evolving spatial trend of suicide rates during 19922012.

\section{METHOD}

\section{Data collection}

We extracted suicide cases (coded X60-X84 in International Classification of Diseases 10th Revision) from the South Korean National Death Registration data set, which were obtained from Statistics Korea, and then retrieved for each case data regarding age, sex and the decedent's address at the governmental administrative district level. We obtained from Statistics Korea official population estimates, stratified by age (5-year age band), sex and administrative districts, as well as official district level maps released by the Statistical Geographic Information Service of Statistics Korea. The earliest available population estimates by district occurred in 1992; hence, our study covered a 21-year study period (from 1992 to 2012). We retrieved for the study period 133456 and 63721 suicides among men and women, respectively, having valid information regarding their residential address coded at the administrative district level.

\section{Geographical system of South Korea and the population distribution within the study period}

The geographical system of South Korea has a hierarchical structure. The highest level includes seven metropolitan cities and nine provinces $(d o)$. Metropolitan cities are considered as larger urban areas with the highest population density. Provinces are partitioned into either city $(s i)$ or smaller administrative districts (gun) depending on population size. In this hierarchical geographical system, all metropolitan cities and several somewhat bigger cities are then partitioned into subdistricts $(g u)$. During the study period, the South Korean government undertook a major reorganisation of its administrative districts. For instance, in 1995 the government integrated a number of small districts into nearby cities to enhance local development, and over the course of ensuing years, many districts either have split into smaller districts or merged into a city due to the growth of the population. According to official maps, there were 270 South Korean administrative districts (si, gu or gun) in 1992, which were reduced to 251 by 2012 .

To allow a direct comparison of demographic and social trends and changes in suicide rates in each district, we constructed a map having consistent boundaries over the 21-year study period, yielding 214 'consistent' districts. On the basis of these 214 'consistent' districts, we calculated the population density of each district ( 5 year averaged) to reflect its level of urbanicity, and then categorised them into five equal quintile regions (1st quintile-the most urbanised region and the 5th quintile-the least urbanised region). We used this approach rather than defining a priori levels of urbanicity (eg, metropolitan cities, cities and rural regions) as the economic and population variations with each level (eg, urban areas) remain considerable. ${ }^{9}{ }^{21}$ Figure 1 shows the geographical location of the 214 districts and its degree of urbanicity during the period 1992-1996. The most urbanised urban region (1st quintile) included mostly areas in Seoul and Busan. Other areas in this region were areas in other metropolises (Daegu and Incheon) and the peripheral areas of Seoul (Gyeonggi province). Areas in the second and third quintiles (less urbanised urban regions) mainly consisted of areas in the seven metropolises and cities (si) within the rural provinces. Most of the areas in the south-west part (Jeonbuk and Jeonnam province), the northern part 


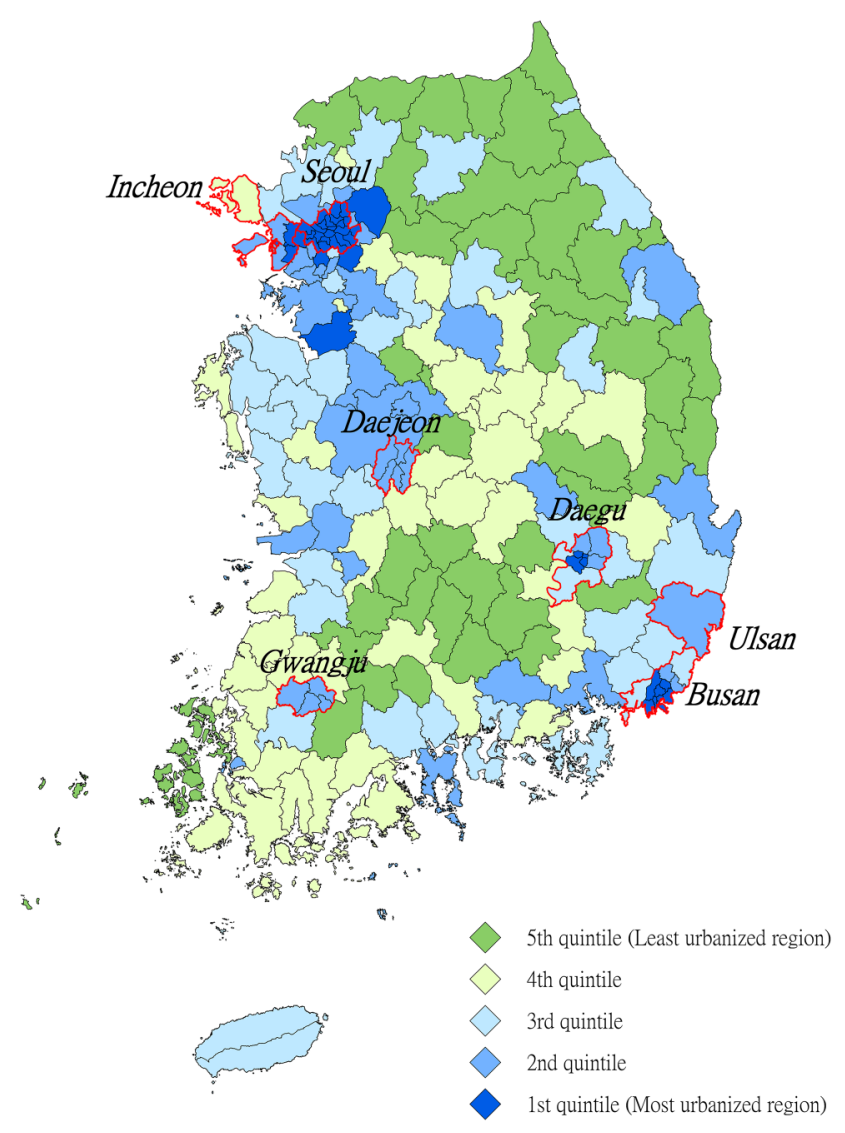

Figure 1 The urbanicity of South Korea (indexed by population density) during the period 1992-1996. Boundaries of the seven metropolitan cities are highlighted in red.

(Gangwon province) and the south-east part of Korea (Gyeongbuk and Gyeongnam province) were in the fourth and fifth quintile categories (rural regions), indicating that they are the least urbanised areas. Changes in the categorisation of these 214 districts at the five equal quintile levels over the years (from 1992 to 2012) were minimal. However, our data reflected that there were changes of the population proportion and composition among these regions, which was most likely a reflection of internal migration, as described in earlier studies (ie, rural-to-urban migration and depopulation in metropolises). ${ }^{30}{ }^{33}$ In particular, we noted that the share of the nation's population in the most densely populated areas (1st quintile) and the rural regions (4th and 5th quintiles) decreased across the periods. In contrast, shares of the population in the less urbanised urban areas (2nd and 3rd quintiles) gradually increased (see online supplementary information). Among the second and third quintile regions, increases of the population mainly derived from the younger-age and the working-age adults (not shown).

\section{Data analyses}

The analysis involved two parts. First, we performed quasi-Poisson regression models to evaluate the crosssectional associations between the degree of urbanicity and suicide rates. Use of the quasi-Poisson modelling instead of the ordinary Poisson modelling was chosen due to the overdispersion issue of the sample. ${ }^{36}$ We specified the models as follows,

$$
\log (\mathrm{y})=\alpha+\beta_{1} \alpha+\beta_{2} \mathrm{~s}+\beta_{3} \log (\mathrm{pd})+\log (\mathrm{pop})
$$

where $y$, as the dependent variable, is the 5 -year-averaged number of suicides of a sex-specific and age-specific group in each district (eg, men in 2024 years of age), and we used the 5-year-averaged population size of the corresponding sex-specific and agespecific group as the offset (pop). Population density (pd) of each administrative district, as the proxy of the degree of urbanicity, was regressed on the dependent variable. Owing to the skewness, the population density estimates were $\log$ transformed. In addition, indicators of age and sex ( $\mathrm{a}$ and $\mathrm{s}$, respectively) were included in the models as covariates. To evaluate whether the crosssectional associations changed across time, we performed the regression models with data segmented into four periods, including the beginning of the study period (1992-1997) and the end of the study period (2008-2012), and two intermediary periods (1998-2002 and 2003-2007), ascertaining the trajectory of the potential changes.

For each regression model, the independent variable of urbanicity (ie, pd of 214 districts) was treated as a continuous variable and thus the categorisation of five equal quintiles as described earlier was not applied. This was to ensure that findings of the association between urbanicity and suicide rate would not be biased by the predefined five equal quintile categorisation. We reported the mortality rate ratio (MRR) for each regression model; MRR larger than 1 indicates a positive association, whereas a smaller than 1 value reflects that the relationship is negative.

For the second part of the analysis, we explored the temporal changes of the suicide rates across regions with various degrees of urbanicity. Here, we relied on the described five equal quintile categorisation (figure 1). We aggregated 5-year suicide statistics and the population estimates to minimise the impact of the year-to-year fluctuations. Also, to adjust the effect of changes in population composition, we applied the standardisation technique, adjusting the suicide rates with the population composition (by 5-year age band) at the beginning of the study period (1992-1996). We then explored the increase/decrease of the 5-year-averaged age-standardised suicide rates from the beginning of the study period (1992-1996) to the end of the study period (2008-2012).

We report our analyses for both sexes and a sexspecific situation. We conducted subgroup analyses for three age groups: $<25$ (youth), aged 25-64 (working-age adults) and $\geq 65$ years (elders). The analysis was implemented using the SAS version 9.3. The significance level for all statistical tests was set at $5 \%$. 


\section{RESULTS}

Table 1 summarises the number of suicides and results of the quasi-Poisson regression models examining the cross-sectional associations between district-specific population density and district-specific suicide rate during 1992-1997, 1998-2002, 2003-2007, and 20082012. On the basis of the entire Korean population, we observed that, after accounting for the effects of age and sex, (log-transformed) population density in all four periods were negatively associated with suicide rates, implying that over the course of years district-level suicide rates were inversely related to the degree of urbanicity. These relationships did not change in any sex-specific fashion. However, the apparent association of urbanicity and suicide rates appear to shrink over the course of years, indicating that the geospatial variation in suicide rate across the 214 districts in South Korea progressively diminished, apparently related to a variety of factors that we will discuss. The attenuation is more notable among women than men. Figure 2 shows the 5-year-averaged age-standardised suicide rates from 1992-1996 to 2008-2012, stratifying by the five equal quintile regions. The overall increases in suicide rates in the five areas over the course of the study period are also included in the figure (in parentheses). Generally, the year-to-year fluctuations in suicide rates across the five places were roughly similar. Also, their increases in suicide rates were comparable, except that the increase in the third quintile region was notably smaller.

From subgroup analyses, we detected that the association of the degree of urbanicity and suicide rates in South Korea differed by age groups and periods. Table 2 summarises the cross-sectional associations of the population density and suicide rates by age groups in all four periods. In addition, for each age group and region, its 5-year-averaged suicide rates from 1992-1996 to 20082012 and its overall increase (in parentheses) are displayed in figure 3 . Since the 5-year-averaged suicide trends by age group and region are similar for both men and women, we only show the results of both sexes in figure 3. As shown in the table, we detected that the degree of urbanicity was inversely related to suicide rate in all four periods among youth younger than 25 years and working-age adults aged 25-64 years; similar to the main analysis, these associations faded across the ensuing years. This fading pattern was more pronounced among women, as the associations between the degree of urbanicity and suicide rates under age 25 years became non-significant during 2003-2007. As observed from figure 3 , the diminished association between the degree of urbanicity and suicide rates among youth is most likely due to a more substantial increase in suicide rates in the more urbanised regions (ie, 1st and 2nd quintiles). For working age adults, increases in suicide rates over the 21-year observatory period were comparatively greater in both the most urbanised (1st) and the least urbanised (5th) regions. In both age groups, i-

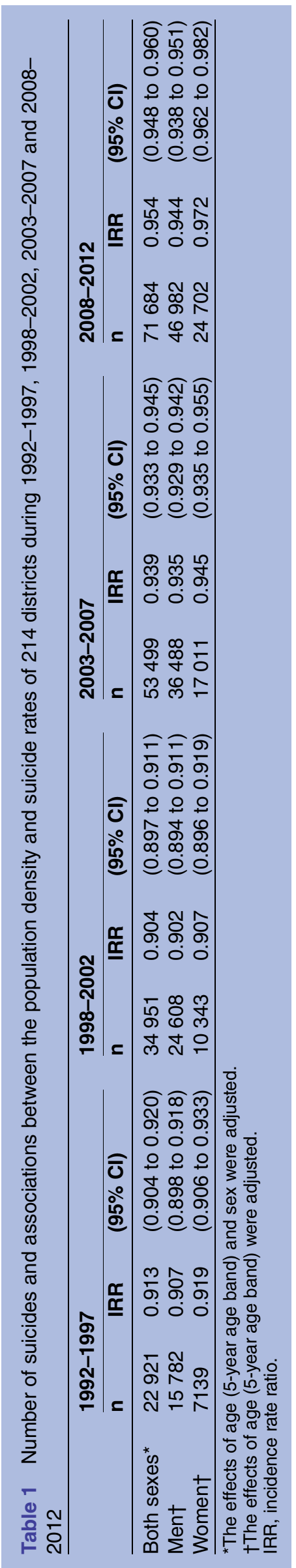




\begin{tabular}{|c|c|c|c|c|}
\hline $\begin{array}{c}1^{\text {st }} \text { Quintile } \\
\text { (Most-urbanized) }\end{array}$ & $2^{\text {nd }}$ Quintile & $3^{\text {rd }}$ Quintile & $4^{\text {th }}$ Quintile & $5^{\text {th }}$ Quintile \\
\hline
\end{tabular}

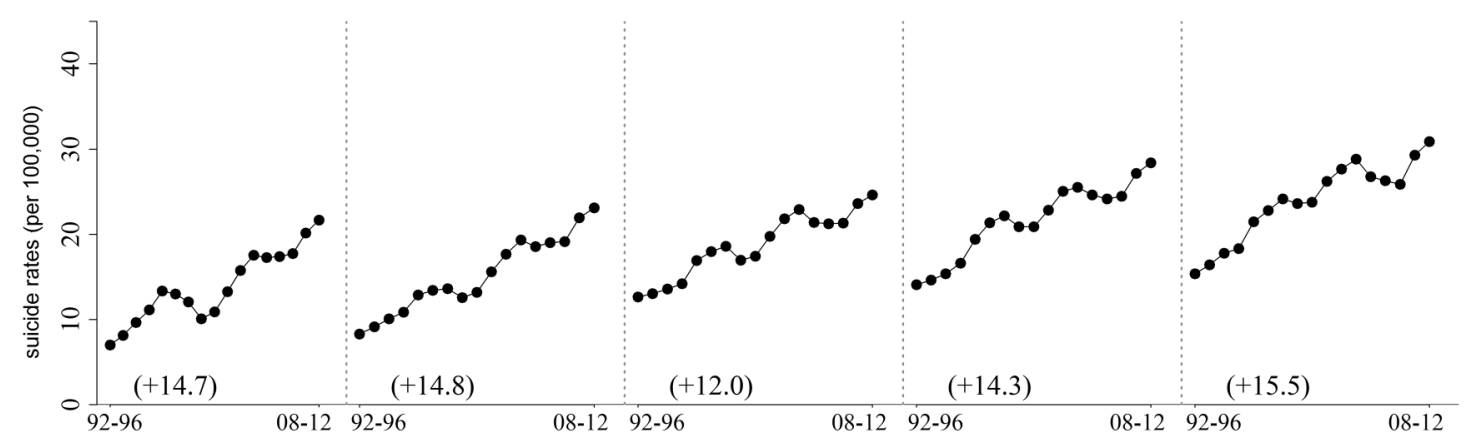

Figure 2 Trends of 5-year-averaged age-standardised suicide rates (from 1992-1996 to 2008-2012) of areas by the 19921996s five equal quintile categorisation.

ncreases in suicide rates were modest in the third quintile region. For elders (aged 65 years and above), the association of the degree of urbanicity and suicide rates changed progressively from positive (ie, 1992-1997 and 1998-2002) to negative (ie, 2003-2007 and 2008-2012); that is, at the beginning of the study period, higher suicide rates among elders occurred in urban settings. As shown in figure 3, changes in the relationship between urbanicity and suicide rate over the study period were due to the far greater increases in suicide rates among elders living in rural regions-even as they also increased in more urban sites as well.

\section{DISCUSSION}

Although previous cross-sectional studies have noted the geospatial inequalities in suicides in South Korea, ${ }^{12} 2022$ this is the first study based on a 21-year observatory period to address the temporal changes of the geospatial pattern in suicide in the nation. Overall, our analyses showed that, among the all Korean population, greater urban density was generally associated with lower rates. This finding is consistent with previous studies in South Korea and elsewhere in the world, ${ }^{6-12}{ }^{22}$ but contrary to studies in several other countries (eg, UK, Denmark) that showed a higher suicide rate among urban dwellers. ${ }^{1-5}$

We observed important changes that pointed to heterogeneous factors, depending on age and sex differences and variations across time, which invite future study. Among youth and working-age adults, the inverse relationship between urbanicity and suicide rates diminished gradually over the study period, a trend more notable among women than men. Trend analysis revealed that reduced spatial inequalities were related to a more rapid increase in suicide rates among the urban dwellers, suggesting that for these groups apparent protective effects of urban residence diminished in the most densely populated cities.

Among Korean older adults, the positive association between urbanicity and lower regional suicide rates detected at the beginning of the study period (eg, 19921996) changed dramatically, as elders' suicide rates in rural regions far surpassed those of their urban counterparts during 2008-2012, as reflected in our trend analysis. One plausible explanation may have involved the rapid depopulation of rural regions in South Korea during recent decades, primarily tied to the movement

Table 2 Associations between the population density and suicide rates of 214 districts, by age groups, during 1992-1997, 1998-2002, 2003-2007 and 2008-2012

\begin{tabular}{|c|c|c|c|c|c|c|c|c|}
\hline & \multicolumn{2}{|c|}{ 1992-1997 } & \multicolumn{2}{|c|}{ 1998-2002 } & \multicolumn{2}{|c|}{ 2003-2007 } & \multicolumn{2}{|c|}{ 2008-2012 } \\
\hline & IRR & $(95 \% \mathrm{Cl})$ & IRR & $(95 \% \mathrm{Cl})$ & IRR & $(95 \% \mathrm{Cl})$ & IRR & $(95 \% \mathrm{Cl})$ \\
\hline \multicolumn{9}{|c|}{ Aged below 25 years } \\
\hline Both sexes & 0.883 & (0.870 to 0.896$)$ & 0.881 & (0.867 to 0.895$)$ & 0.958 & (0.944 to 0.973 ) & 0.971 & (0.957 to 0.986$)$ \\
\hline Men & 0.885 & (0.869 to 0.902$)$ & 0.870 & (0.852 to 0.889$)$ & 0.938 & (0.918 to 0.958$)$ & 0.970 & (0.956 to 0.985$)$ \\
\hline Women & 0.881 & (0.862 to 0.901$)$ & 0.899 & (0.878 to 0.921$)$ & 0.985 & (0.964 to 1.006$)$ & 0.970 & (0.956 to 0.985$)$ \\
\hline \multicolumn{9}{|c|}{ Aged $25-64$ years } \\
\hline Both sexes & 0.869 & (0.861 to 0.877$)$ & 0.864 & (0.857 to 0.871$)$ & 0.912 & (0.906 to 0.919$)$ & 0.946 & (0.940 to 0.952$)$ \\
\hline Men & 0.870 & (0.861 to 0.880$)$ & 0.867 & (0.859 to 0.875$)$ & 0.911 & (0.903 to 0.918$)$ & 0.942 & (0.933 to 0.951$)$ \\
\hline Women & 0.863 & (0.850 to 0.877$)$ & 0.851 & (0.839 to 0.863$)$ & 0.912 & (0.902 to 0.923$)$ & 0.942 & (0.933 to 0.951$)$ \\
\hline \multicolumn{9}{|c|}{ Aged 65 or above years } \\
\hline Both sexes & 1.113 & (1.090 to 1.136$)$ & 1.018 & (1.004 to 1.033 ) & 0.973 & (0.964 to 0.982 ) & 0.952 & (0.943 to 0.960$)$ \\
\hline Men & 1.108 & (1.079 to 1.138$)$ & 1.021 & (1.002 to 1.040$)$ & 0.973 & (0.961 to 0.985$)$ & 0.954 & (0.940 to 0.968$)$ \\
\hline Women & 1.119 & (1.083 to 1.157$)$ & 1.013 & (0.991 to 1.035$)$ & 0.972 & (0.957 to 0.987$)$ & 0.954 & (0.940 to 0.968$)$ \\
\hline
\end{tabular}




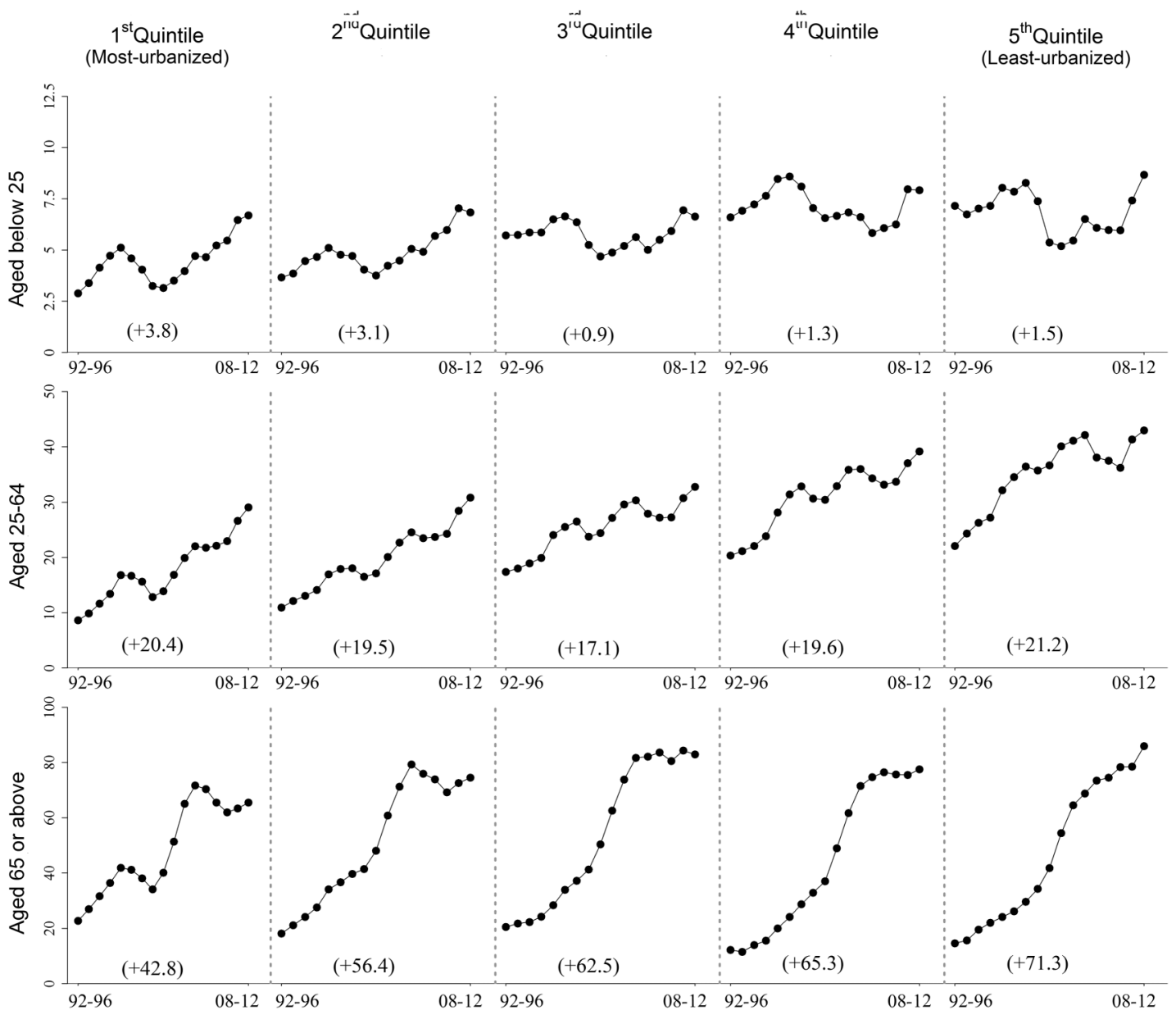

Figure 3 Trends of 5-year-averaged age-specific suicide rates (from 1992-1996 to 2008-2012) of areas by the 1992-1996s five equal quintile categorisation.

of working-age adults and their children seeking employment and economic opportunities. ${ }^{30}$ Like many countries, South Korea, with its industrialisation and urbanisation, has undergone a powerful demographic transformation and experienced a reduced dependence on family-based agriculture. Rural regions have seen a relative concentration of less mobile older ages, with diminished support from younger generations, as well as shrinking peer networks. As recently reported, social isolation has become a major problem for Korean elders, especially in rural regions. ${ }^{37}$ Financial hardship and poverty are common among elders-now a major recognised problem in contemporary Korean society. ${ }^{38-40}$ Cho found that almost half of the households that are headed by older persons, which are concentrated in rural areas, are in poverty. In a related fashion, more than $60 \%$ of the elderly population of South Korea was estimated to be poor. ${ }^{3941} 42$ Our findings of a divergent trend of elderly suicide between more urbanised and less urbanised areas plausibly represent what we see as an unintended adverse consequence of the country's rapid economic growth. ${ }^{39}$

In our earlier study, we reported the likelihood of a gradually diminishing underestimation in Korea's official suicide statistics (ie, they have become more accurate), due to improving death examination processes and classification. ${ }^{43}$ Were any of the changes we observed in this new study, such as the apparently greater increases among rural dwelling elders, disproportionately influenced by improved postmortem methods? We explored this situation using previously defined methods: ${ }^{43}$ Changes in death classification occurred both in urban and rural regions (see online supplementary appendix). The overall proportional changes in the three death categories (ie, accidental deaths, undetermined deaths and suicides) remained fairly consistent across the five regions. While we still cannot pinpoint the exact extent of changes in death classification that may have affected our current results, our analyses suggested that the impact of improving classification was systematic and operating at a national level, and thus less likely to substantially account for observed changes in geospatial patterns, especially as there were differing patterns of change for youth, adults and older persons.

In the face of industralisation and modernisation, traditional Confucian values rooted in South Korean society have been increasingly challenged by Western values that are more individually oriented. Some have reported 
that this transition in cultural values has created ambiguous social expectations (ie, cultural ambivalence), which can become a source of distress provoking suicidal behaviour, both among elders and younger persons. ${ }^{44} 45$ Park argued that this conflicting ideal of gender equality and Confucian tradition may be one plausible reason for the recent rapid increase in young women's suicides. ${ }^{45}$ Whether such cultural ambivalence accounts for the more rapid increase among urban-dwelling women or rural elders who are 'left behind', as detected in this study, deserves further exploration.

Since this is an ecological study, it is imperative not to generalise our findings to the individual level, avoiding any ecology fallacy. Also, despite the improving death classification, under-reporting of suicides due to misclassification most likely continues to influence Korean official statistics. This study provides guidance for important quantitative and qualitative investigations that can inform potential preventive interventions.

\section{CONCLUSION}

Looking beyond the immediate questions that we have raised for further investigation, we also see several broad implications of our findings. Suicide in South Korea has been a dynamic process during recent decades occurring in the midst of rapid economic expansion, showing increases across the life course for men and women, and regional variations apparently linked to migration and urbanisation. There have been dramatic increases in suicide rates, especially among rural elders, in the context of large increases for all ages and both sexes. These are reminiscent of changes described for Japan. With the ageing of the South Korean population, we foresee great challenges ahead when planning how best to prevent continuing overall increases in the national rate. A demographic tsunami may be difficult to avoid in South Korea, as it will be in many nations.

South Korea has been an economic dynamo, with apparent fundamental transformations of the nation's demographic, economic and social structure. Other countries with Confucian traditions, most notably China, ${ }^{46}$ also are experiencing powerful economically driven internal migrations-and on an unprecedented scale. Understanding the consequences of migration, economic support and poverty, social isolation, and family structure will be key elements for optimally designing, implementing and rigorously evaluating future suicide prevention efforts in these nations.

Acknowledgements The authors would like to thank Lee Ssu Lang for data analysis support.

Contributors CHC, EDC, SY and PSFY were involved in the study design and the analysis and interpretation of data. $\mathrm{CHC}$ and EDC were involved in drafting the article. $\mathrm{CHC}$ and EDC were involved in the final approval of the version to be published.

Funding Supported in part by CDC grant R49 CE002093 (EDC, PI) and NIH grant D43 TW009101 (EDC, PI).

Competing interests None declared.
Ethics approval Ethical approval was obtained from the Human Research Ethics Committee for Non-Clinical Faculties, The University of Hong Kong (reference no. EA341214).

Provenance and peer review Not commissioned; externally peer reviewed.

Data sharing statement No additional data are available.

Open Access This is an Open Access article distributed in accordance with the Creative Commons Attribution Non Commercial (CC BY-NC 4.0) license, which permits others to distribute, remix, adapt, build upon this work noncommercially, and license their derivative works on different terms, provided the original work is properly cited and the use is non-commercial. See: http:// creativecommons.org/licenses/by-nc/4.0/

\section{REFERENCES}

1. Isometsa $\mathrm{E}$, Heikkinen $\mathrm{M}$, Henriksson $\mathrm{M}$, et al. Differences between urban and rural suicides. Acta Psychiatr Scand 1997;95:297-305.

2. Mortensen PB, Agerbo E, Erikson T, et al. Psychiatric illness and risk factors for suicide in Denmark. Lancet 2000;355:9-12.

3. Qin P. Suicide risk in relation to level of urbanicity-a population-based linkage study. Int J Epidemiol 2005;34:846-52.

4. Middleton N, Sterne JA, Gunnell DJ. An atlas of suicide mortality: England and Wales, 1988-1994. Health Place 2008;14:492-506.

5. Pearce J, Barnett R, Jones I. Have urban/rural inequalities in suicide in New Zealand grown during the period 1980-2001? Soc Sci Med 2007;65:1807-19.

6. Chang SS, Sterne JA, Wheeler BW, et al. Geography of suicide in Taiwan: spatial patterning and socioeconomic correlates. Health Place 2011;17:641-50.

7. Yip PS, Callanan C, Yuen HP. Urban/rural and gender differentials in suicide rates: east and west. J Affect Disord 2000;57:99-106.

8. Phillips JA. Factors associated with temporal and spatial patterns in suicide rates across U.S. States, 1976-2000. Demography 2013;50:591-614.

9. Kim MH, Jung-Choi K, Jun HJ, et al. Socioeconomic inequalities in suicidal ideation, parasuicides, and completed suicides in South Korea. Soc Sci Med 2010;70:1254-61.

10. Watanabe N, Hasegawa $K$, Yoshinaga $Y$. Suicide in later life in Japan: urban and rural differences. Int Psychogeriatr 1999;7:253-61.

11. Fukuda $Y$, Nakamura K, Takano T. Cause-specific mortality differences across socioeconomic position of municipalities in Japan, 1973-1977 and 1993-1998: increased importance of injury and suicide in inequality for ages under 75. Int $J$ Epidemiol 2005;34:100-9.

12. Hong J, Knapp M. Geographical inequalities in suicide rates and area deprivation in South Korea. J Ment Health Policy Econ 2013;16:109-19.

13. Page A, Morrell S, Taylor R, et al. Further increases in rural suicide in young Australian adults: Secular trends, 1979-2003. Soc Sci Med 2007;65:442-53.

14. Singh GK, Siahpush M. Increasing rural-urban gradients in US suicide mortality, 1970-1997. Am J Public Health 2002;92:1161-7.

15. Kapusta ND, Zorman A, Etzersdorfer E, et al. Rural- urban differences in Austrian suicides. Soc Psychiatry Psychiatr Epidemiol 2008;43:311-18.

16. Pesonen TM, Hintikka J, Karkola KO, et al. Male suicide mortality in eastern Finland-urban-rural changes during a 10 -year period between 1988 and 1997. Scand J Public Health 2001;29:189-93.

17. Suzuki E, Kashima S, Kawachi I, et al. Social and geographical inequalities in suicide in Japan from 1975 through 2005: a census-based longitudinal analysis. PLOS ONE 2013;8:e63443.

18. Chen YY, Kwok CL, Yip PS, et al. A test of the substitution hypothesis: an analysis of urban and rural trends in solid/liquid poisoning suicides in Taiwan. Soc Sci Med 2013;96:45-51.

19. Park BC, Lester D. Rural and urban suicide in South Korea. Psychol Rep 2012;111:495-7.

20. Kim MD, Hong SC, Lee SY, et al. Suicide risk in relation to social class: a national register-based study of adult suicides in Korea, 1999-2001. Int J Soc Psychiatry 2006;52:138-51.

21. Cheong KS, Choi MH, Cho BM, et al. Suicide rate differences by sex, age, and urbanicity, and related regional factors in Korea. $J$ Prev Med Public Health 2012;45:70-7.

22. Lee J, Lee WY, Noh M, et al. Does a geographical context of deprivation affect differences in injury mortality? A multilevel analysis in South Korean adults residing in metropolitan cities. $J$ Epidemiol Community Health 2014;68:457-65.

23. Choi $\mathrm{KH}, \mathrm{Kim} \mathrm{DH}$. Trend of suicide rates according to Urbanity among Adolescents by Gender and Suicide Method in Korea, 19972012. Int J Environ Res Public Health 2015;12:5129-42. 
24. Taylor R, Page A, Morrell S, et al. Social and psychiatric influences on urban-rural differentials in Australian suicide. Suicide Life Threat Behav 2005;35:277-90.

25. Middleton N, Sterne JA, Gunnell D. The geography of despair among 15-44-year-old men in England and Wales: putting suicide on the map. J Epidemiol Community Health 2006;60:1040-7.

26. Wilkinson D, Gunnell D. Youth suicide trends in Australian metropolitan and non-metropolitan areas, 1988-1997. Aust N Z J Psychiatry 2000;34:822-8.

27. Levin $\mathrm{KA}$, Leyland $\mathrm{AH}$. Urban/rural inequalities in suicide in Scotland, 1981-1999. Soc Sci Med 2005;60:2877-90.

28. Victor C, Scambler S, Bond J, et al. Being alone in later life: loneliness, social isolation and living alone. Rev Clin Gerontol 2000;10:407-17.

29. Luanaigh CÓ, Lawlor BA. Loneliness and the health of older people. Int J Geriatr Psychiatry 2008:23:1213-21.

30. Kwon TH, Jun KH. Rural-Urban Migration and the Social Mobility of Individuals in the Republic of Korea: An Analysis of Life History Data. Korean Journal of Population and Development 1990;19:113-34.

31. Palley HA. Social policy and the elderly in South Korea: Confucianism, modernization, and development. Asian Survey 1992:32:787-801.

32. Han GH. Tradition and modernity in the culture of aging in Korea. Korea J Popul Dev 1996;25:41-57.

33. Chun H, Doyal L, Payne S, et al. Understanding women, health, and social change: the case of South Korea. Int $J$ Health Serv 2006;36:575-92.

34. Moon SS, Park SM, Cho SI. The association of social support and activities with health in South Korea: differences in age and gender. $J$ Biosoc Sci 2010;42:409-24.

35. Do YK, Malhotra C. The effect of coresidence with an adult child on depressive symptoms among older widowed women in South Korea: an instrumental variables estimation. J Gerontol B Psychol Sci Soc Sci 2012;67:384-91.
36. Chung S. Residential status and depression among Korean elderly people: a comparison between residents of nursing home and those based in the community. Health Soc Care Community 2008;16:370-7.

37. Statistic Korea. Korean Social Trends: Statistics Korea, 2014 [in Korean].

38. Choi SJ. Aging and social policy in Korea. Korea J Popul Dev 1996;25:1-25.

39. Kim H. Intergenerational transfers and old-age security in Korea. The Economic Consequences of Demographic Change in East Asia, NBER-EASE.Vol 19. University of Chicago Press, 2010: 227-78.

40. Suh MK. The elderly population in Korea: their health status and kin-based social support. Korea J Popul Dev 1992;21:175-96.

41. Cho Y-S. The realities of recent elderly poverty and policy implications. The 8th Conference of Korean Labor and Income Panel Study; 2007.

42. Kim EH-W, Cook PJ. The continuing importance of children in relieving elder poverty: evidence from Korea. Ageing Soc 2011;31:953-76.

43. Chan $\mathrm{CH}$, Caine ED, Chang SS, et al. The impact of improving suicide death classification in South Korea: a comparison with Japan and Hong Kong. PloS one 2015;10:e0125730. doi:101371/journal. pone. 0125730

44. Cho HJ. Children in the examination war in South Korea: a cultura analysis. In: Stephens S, ed. Children and the politics of culture. Princeton: Princeton University Press, 1995:141.

45. Park BC. Cultural ambivalence and suicide rates in South Korea In: Colucci E, Lester D, eds, Culture and suicide. Cambridge, MA: Hogrefe, 2013:237-62.

46. Caine ED. Changing the focus of suicide research in China from rural to urban communities. Shanghai Arch Psychiatry 2013;25:174-5 